\title{
Teaching and Implementing Ideation in Entrepreneurship: A Systematic Approach
}

\author{
Ozlem Ogutveren-Gonul \\ Close School of Entrepreneurship \\ Drexel University \\ Pearlstein Building, Suite 402 \\ 3218 Market St, Philadelphia, PA 19104 \\ Email: oo49@drexel.edu
}

Received: August 29, 2018 Accepted: December 28, 2018 Published: February 4, 2019

doi:10.5296/jebi.v5i2.13245 URL: http://dx.doi.org/10.5296/jebi.v5i2.13245

\begin{abstract}
Idea creation is significant to all disciplines, yet it is even more crucial for entrepreneurs since the process of entrepreneurship requires new and novel ideas in all phases. Ideation should be taught and implemented in an intentional and systematic approach in order to increase the efficiency of idea generation in entrepreneurial activity. The purpose of this paper is to present a systematic approach to ideation which may be used both by instructors and practitioners in teaching and implementing ideation. Systematic ideation is comprised of a series of steps including observation, building the right ideation team, using multiple thinking methods and idea generation methods together and validating the idea for further improvement. Many of the entrepreneurship programs teach students the process of entrepreneurship after the individual comes forth with an idea, focusing on developing personal skills and business models required for a successful venture. Little attention and focus is dedicated to the initial step of idea creation. Application of a systematic approach to teaching and implementing ideation would fill this gap in entrepreneurship education and field resulting in creation of ideas with better chances of success.
\end{abstract}

Keywords: Ideation, Innovation, Creativity, Thinking Methods, Entrepreneurship Education

\section{Introduction}

Creating new ideas are important in many disciplines. Individuals have new ideas every day -whether these ideas are small or big, make money or solve social problems, are disruptive innovations or just compete with other existing ideas, still, they are born as a result of an 
opportunity recognition, necessity or chance. Entrepreneurs turn these ideas into reality through new and innovative business models and processes. It has been an ongoing debate whether creativity is a personal trait and some people are born with it or it can be taught and developed through personal experiences. There is no doubt that people with creative skills are at an advantage to come up with original and innovative ideas. Nevertheless, using the precise methodology and tools will increase the chances of new idea creation for all individuals. Yet, ideation should be regarded as a structured process in which people from all disciplines, especially entrepreneurs, can practice in all phases of their projects and ventures.

Entrepreneurship education gained renewed interest in the US over the last two decades as both the result of students' increasing interest in the field and increasing awareness of the public authorities about the significance of entrepreneurship in economic development and wellbeing (Fayolle, Gailly \& Lassas-Clerc, 2006; Dobson, Jacobs \& Dobson, 2017). As a result of this rising interest, entrepreneurship is now considered as an exclusive discipline, independent from other fields in business (Morris, Webb, Fu \& Singhal, 2013), requiring a differentiated and more experiential education curriculum. One of the differentiator components of entrepreneurship education is the inclusion of ideation methodology into every level of the programs. Courses focusing on creativity, ideation and opportunity recognition have high impact on teaching entrepreneurship by providing students with concepts and tools related to creativity and engaging them in creative activities (Miyasaki, 2014).

This paper first reviews some of the approaches to the origins of ideas, idea development, creativity, innovation and the interaction of these concepts to provide e better understanding of the ideation process. Second part of the paper proposes a systematic ideation approach with multiple phases. Finally, a discussion about the importance of integrating a systematic ideation process into entrepreneurship education is presented.

\subsection{Origins of Ideas: How Do We Develop Ideas?}

Where do ideas come from? The origin of ideas has been a topic of interest for philosophers and researchers for many centuries. Prominent philosopher John Locke refers to experiences as the basic sources of ideas. He states that "all ideas come from sensation and reflection" (Link, 2017, p. 280). Locke argues that observing our experiences, both through external sensations and internal perceptions of our minds, builds the foundations of new ideas. Similarly, David Hume proposes that all ideas are results of our impressions -lively perceptions of our feelings and experiences- of the world (Link, 2017, p. 280). Descartes describes ideas as modes of thinking: "Descartes distinguishes between the 'formal' and 'objective' reality of ideas: ideas have formal (or intrinsic) reality by virtue of being modes of thought or mental events; and they have objective reality by virtue of their object or representational content" (Jolley, 1998, p. 13-14).

There is not a common understanding among scholars about the process of new idea development. Some portion of the idea development process is a consequence of an individual's cognitive mechanisms and some part of it relies on personal traits/abilities such as creativity and opportunity recognition. Advocating the cognitive approach, Papo (2007, p. 
163) suggests that "ideas arise in the context of specific relationships between structure, dynamics and function of brain networks at various temporal and spatial scales, and as a result of goal-directed learning-dependent modulations of conflicting structural and dynamical systemic tendencies between high susceptibility to change and long-term memory".

Creativity is frequently seen as a premise and a predictor of new idea development process. There are mainly two different categories of definitions for creativity among researchers. One stream of research defines creativity as "socially recognized achievement in which there are novel products to which one can point as evidence, such as inventions, theories, buildings, published writings, paintings, sculptures, laws, institutions, medical and surgical treatments" (Barron \& Harrrington, 1981, p. 441). This category of definitions frequently focuses on a useful end-product as a result of the creative process. The second group of definitions view creativity "as an ability manifested by performance in critical trials, such as tests, contests, etc., in which one individual can be compared with another on a precisely defined scale" (Barron \& Harrrington, 1981, p. 441). The latter category of definitions points at high performance standards and usually a rewarding personal accomplishment against others. These definitions have revolved around and conceptualized through a variety of perspectives. Some studies attempt to explain creativity through unique personal characteristics of an individual (Barron, 1955; MacKinnon, 1965; Barron \& Harrington, 1981). Other approaches to defining creativity focus on the influence of social environment on creative behavior (Woodman, Sawyer \& Griffin 1993; Amabile, Conti, Coon, Lazenby \& Herron, 1996), cognitive operations (Wallas, 1926; Mednick, 1962, Finke, Ward \& Smith, 1992) or the socio-psychological foundations which is a combination of social factors such as the environment and psychological factors (Amabile, 1996).

Some of the above approaches to creativity reinforce the belief that creativity cannot be developed or enhanced as it is a given characteristic or is related to the IQ level of the individual. Stouffer, Russell and Oliva (2004, p. 5) address this view by indicating that "it is far too common a notion that creativity is an inherent gift that one either does or does not possess" Consequently, most individuals who recognize themselves as uncreative, do not take any action on self-growth towards a more creative attitude and do not participate in intentional idea development attempts. Counter to this view is the prospect that creativity is a process (Osborn, 1953; Torrance, 1963; Farid, El-Sharkawy, \& Austin, 1993) and "not only can it be taught, it is taught effectively at all levels of education, from kindergarten to graduate school" (Stouffer, et al., 2004, p.5).

Creativity or creative process has led to a further notion: innovation. Although sometimes used interchangeably, the term 'innovation' is often used instead of creativity when approaching technical matters to describe the process that leads to insight or progress in a field, with a technique, or with a physical product (Stouffer, et al., 2004, p.2).

Schumpeter, one of the prominent economists and researchers, well known for his theory of entrepreneurship regards innovation as the basis for economic change and development (Parayil, 1991). Schumpeter distinguishes innovations from inventions as follows: 
"innovations are the composite of two worlds, namely, the technical, and the business; so when only a change in technology is involved, this is just an invention; but as soon as the business world is involved, it becomes an innovation" (Janzsen, 2000). Consequently, Schumpeter conceptualizes innovation as the commercialization of new inventions through development of new business models. Crossan and Apaydin (2010) derived a comprehensive definition of innovation through their extensive literature review on innovation. According to the authors, innovation is the production or adoption, assimilation, and exploitation of a value-added novelty in economic and social spheres; renewal and enlargement of products, services, and markets; development of new methods of production; and establishment of new management systems. It is both a process and an outcome (p. 1155).

Creativity is frequently considered as a premise for ideation, and innovation is the expected outcome. Although partially correct, this prediction is far from explaining the creativity-ideation-innovation association in creating new and novel ideas. Papo (2007: 174) describes ideas as 'goal-oriented acts of creativity' suggesting that ideas are created in contemplation of solving a problem or as a result of opportunity recognition. Idea creation is a planned, goal-oriented action, whether or not the creator is aware of such action. Sometimes the ideator is given a specific problem at hand to be solved, but otherwise his mind prepares itself for the ideation process through a sequence of observations, experiences and environmental awareness -as Louis Pasteur has famously indicated that "chance favors only the prepared mind". Creativity is only one of the tools in facilitating the ideation process, and cannot avail the presented opportunities alone. Systematic thinking, awareness and educated observation transforms creativity into the commencement of original ideas. Thus, ideation should be regarded as a systematic, conscious and intentional process.

\subsection{Ideation: A Systematic Approach}

Creativity, invention, innovation and idea generation are all interrelated terms and processes with overlapping definitions, vague nuances and intertwined boundaries, especially when it comes to implementation. Ideation, commonly defined as developing ideas for innovation (Bjork, 2012), is a systematic and methodological approach to incorporate these terms and can be used to develop an approach to integrate idea generation into all phases of business, entrepreneurship and education. Ideation approach attempts to facilitate the creation of novel and valuable ideas through an intentional process where ideators will combine different ways of thinking and use unique techniques in generating ideas to advance their fields.

Bergendahl and Magnusson (2015) argue that innovation and new idea development in most of the industries have become so multidimensional that it is no longer about the product and the process alone. Companies need new ideas at every stage of their processes and therefore idea generation is not limited to the product development, innovation and R\&D departments of the organizations. "Innovation is manifested in terms of new services, markets, business models and organizational forms and a consequence of this is that a wider range of employees throughout organizations can contribute" (p. 87) to the ideation process. Koen et. al (2001) suggest that idea generation is one of the greatest areas of weakness in innovation since the companies typically have highly unstructured ideation processes, full of uncertainty 
and very chaotic. Most of the entrepreneurs and corporate innovators (often called intrapreneurs) first have an idea and then start to plan for further stages of their ventures/projects instead of planning strategically for idea creation. The result of this need is a more intentional, attentive and dedicated approach to systematic ideation within the organizations to continuously come up with ideas and provide abiding competitive advantages.

Although, it is a natural process without the need for conscious effort for some people, ideation appears to happen through a concerted effort and necessitate a more systematic approach and use of special techniques for most of us (Mahon, 2017). Systematic ideation approach tend to be a proactive approach to idea creation replacing the reactive approach to wait for the new ideas to emerge spontaneously by chance or luck in a 'eureka moment'. A systematic ideation approach with five consecutive phases will be presented below. This approach should be integrated into entrepreneurship education to enhance the ideation and creative thinking skills of future entrepreneurs.

\subsection{Observation/Interaction Phase (Socialization)}

Opportunity recognition is considered as one of the main determinants of new idea creation and the more dynamic the environment becomes, the tougher it is to notice and understand the opportunities around us (Dayan, Zacca \& Di Benedetto, 2013). Ideation is an interactional process and observation is the main tool enhancing the interaction between a person and his environment leading to the realization of opportunities around him. Person-context interaction should exhibit open-minded thinking and an ability to combine unrelated ideas (Guo, Su \&Zhang, 2017, p.31). Discovery of new ideas is the result of our observance of what people need, what people like and what works/not works for them. The first step in teaching the intentional ideation process is to present participants the need to think differently and to have unique perceptions of the problems and opportunities around them.

Entrepreneurs live in a genuinely complex environment and this complexity increases by day. Strong observational skills help them to make sense out of complexity, relate and associate distinct observations into ideas. Ideators frequently need to work with problems that do not have one unique solution and may be approached with multiple aspects. Effective use of memory becomes important to recall past observations to associate them with an existing problem or opportunity. Results of Dayan et al.'s (2013) research indicate that mediating effect of access to and possession of resources only play a significant role on entrepreneurial creativity (pertaining to the creation of new ideas and products) if combined with sufficient alertness to opportunities.

Machlup (1980) accentuates the importance of observations in building personal knowledge leading to creation of new ideas. He calls this type of knowledge "knowledge at no cost" obtained by only being alive, awake and aware of what goes around us. Perceptive, observing and reflecting people who are alert of their environment has continuous access to free knowledge around them. Observation is a process of planned, methodological watching that involves constraints to improve accuracy (Weick, 1968, p. 358). The difference between seeing/watching and observing is the planned nature of the latter process to understand the 
details and collect data to use in developing new phenomena.

Random observation in which we do not make sense of what we see and drive results should be distinguished from systematic observation. During random observation, we only notice the details and note the observation. Observation becomes systematic to the degree that plans for selection, provocation, recording, and encoding are both explicit and preset (McCall, 1984, p. 265), regarding that the process is carried out in a conscious and intentional manner. In systematic observation, we purposefully look for clues about the environment, people, what they need, what they like and prefer, what they suffer from and how we can provide them with solutions. Systematic observation is a tool to collect data from our own environment with trained eyes to see what is not working and how it can be fixed. Intentional and educated observation increases our alertness and perceptiveness, and advances our opportunity recognition skills.

\section{Teambuilding}

Though it can be obtained through individual effort, innovation -and ideation- is normally a collective endeavor (Leonard \& Sensiper, 1998; Bjork, 2012). Creativity and innovation has a substantial social component. Collective creativity and innovation are results of social relations, activities (Mascia, Magnusson \& Bjork, 2015) and team work whereby interactions with people and environment facilitate idea creation. Collaborative ideation is needed (Bergendahl \& Magnusson, 2015) to expand the ideational performance capacity of a group.

Collective and collaborative ideation through team work enhances diversity in knowledge creation. Two types of diversity exist within teams working in ideation tasks. The first one is informational diversity which refers to differences in characteristics such as educational background and functional experience and is related to the kind of concrete information each member brings to the team. Social category diversity refers to demographic differences such as gender, age and tenure among the members of the team (Guo, et al., 2017). Informational diversity in teams is less visible and more task-related than social category diversity. Both types of diversity increase the availability of various valuable sources of information. Obtaining and combining diversified knowledge increases the chance of new idea creation.

Bjork (2012) implies that knowledge diversity of team members shows a curvilinear relationship with innovation (Dell'Era \& Verganti, 2010) and has an important impact on creating novel ideas (Nieto \& Santamaria, 2007). Knowledge diversity expedites the innovation process through facilitation of unique linkages and associations between distant ideas and increases absorptive capacity, the ability to recognize the value of new, external information, assimilate it, and apply it to commercial ends (Cohen \&Levinthal, 2000).

Cross-functionality and inter-disciplinarity are important indicators of diversity for an ideation team. When individuals from different fields successfully manage to connect these fields to come up with new creative insights, innovation occurs. Johansson (2004) refers to the overlap of different fields as the "intersection". Team members "step into the intersection by associating concepts from one field with concepts in another. The intersection than becomes a place for wildly different ideas to bump into and build upon each other" (p. 16). 
Valacich, Jung \& Looney (2006) indicate that team ideation is typically a combination of additive and disjunctive tasks. Group performance regarding ideation capacity can be measured as either the quantity (i.e., additive) and/or quality (i.e., disjunctive) of the ideas generated. Both the quality and the quantity of the ideas, on the other hand, depend on the coherence of the group and how well they work together. Increasing familiarity among team members is an effective means to increase team coherence. Team members need to understand and know each other to stimulate shared imagination resulting in the creation of new ideas. This familiarity does not necessarily mean that they should know each other closely, but getting familiar with each other's knowledge, experiences, strengths and weaknesses will provide members with information to complement the group for the ideation process.

\section{Using Multiple Thinking Methods Together}

Types and sequence of thinking methods used during an ideation process differs according to a number of variables: the composition of the team, the nature of the idea/problem addressed, time limitations, expectations of the stakeholders and the resources required. The crucial skill for the ideation team is to be able to use multiple thinking skills together at once or in a sequence as required by the task and be able to switch between thinking styles efficiently. In a team setting, each member of the team will have different levels of strength in using a variety of thinking methods and skills. Divergent thinking, convergent thinking, critical thinking, lateral thinking, visual thinking and design thinking are among these alternate modes of thinking.

a) Divergent and Convergent thinking: In earlier studies of thinking methods, as one of the pioneers of the field, Guilford (1950) differentiated between divergence and convergence and proposed two general types of thinking. Divergent thinking allows the individual to generate as many new ideas as possible, in a context where more than one solution is acceptable (Colzato, Ozturk \& Hommel, 2012). The main goal is to explore as many aspects of the concept as possible. The divergent thinker allows his mind to wander around in any direction and associate different thoughts and concepts, finding unique combinations and relations. Since, arriving at one single correct solution is not the ultimate goal, divergent thinkers prefer open-ended questions allowing for a variety of novel answers (Robertson, 2013). The thinker is not given limitations and is not forced to focus on any certain direction. It is a free-form of thinking with a multidimensional construct (Runco, 1991). Developing a number of unexpected and uncommon solutions to a problem (ideational originality), being able to switch between categories when giving answers to a question (ideational flexibility), and producing many answers at once regarding a question (ideational fluency) are among the dimensions of divergent thinking (Runco 1991; Robertson, 2013).

Convergent thinking is the process of generating one possible solution to a particular problem. Convergent thinker is expected to 'converge' his thoughts on the appropriate answer (Robertson, 2013). The ultimate goal is to find the single best solution to a given problem, emphasizing speed and relying on high accuracy (Colzato, et al., 2012). Accordingly, 
convergent thinkers prefer specific, well-defined questions with boundaries. It is an analytical, usually deductive, mode of thinking, in which ideas are tested for their logical validity. It is a systematic form of thinking, frequently following a set of rules. Figure 1 shows how divergent thinking and convergent thinking are used together to arrive at a solution in comparison with linear thinking, in which the connection between the problem and the solution is direct and the only one correct solution is reached through a series of predetermined steps. Considering multiple solution options is not needed.

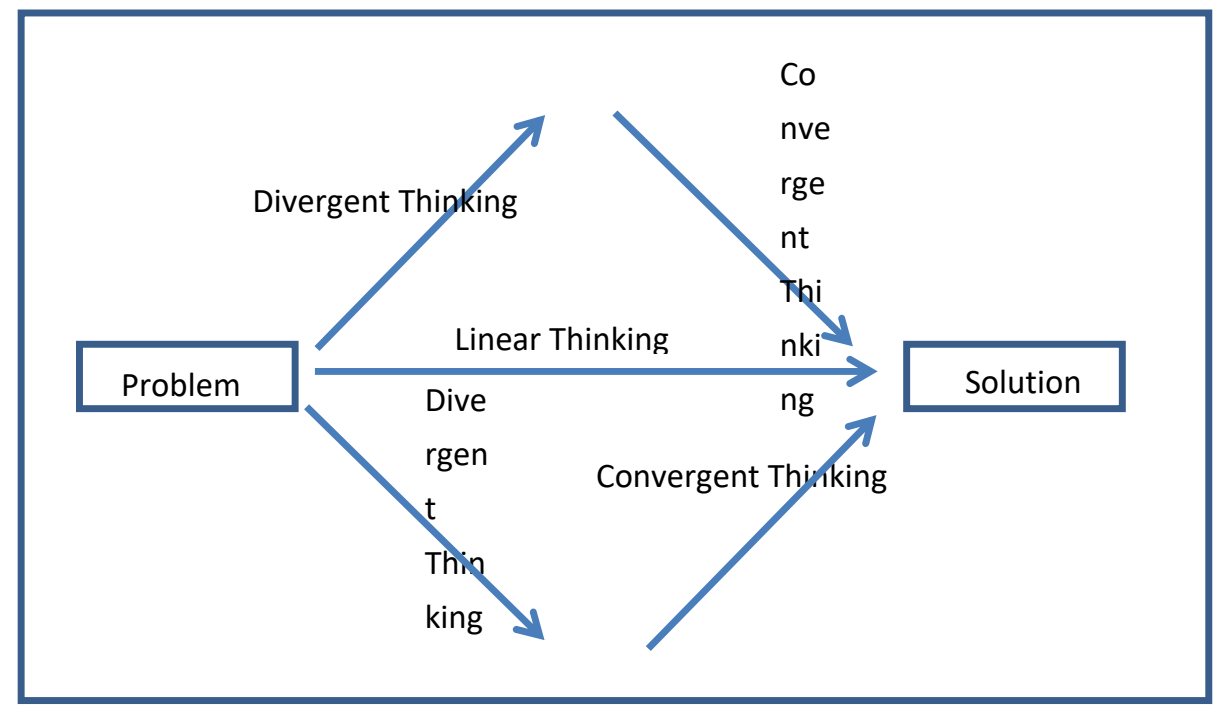

Figure 1. Divergent and Convergent Thinking vs Linear Thinking (Mahon, 2017, p.11)

Basadur, Runco \& Vega (2000) indicate that active divergence is the generation of options without evaluation (deferring judgment) and active convergence, is the application of judgment to the generated options to select the most significant options. These two modes of thinking usually follow one another to complete the full cycle of thinking for ideation. IQ tests are tended to favor convergent thinkers and creativity tests are designed to measure the ability of divergent thinkers (Robertson, 2013). In the full cycle of the ideation process, creativity requires divergent thinking while designing the ideas for successful executability and implementation requires convergent thinking.

a) Critical thinking: Critical thinking is defined on the basis of rational thinking. It is a reasonable, reflective thinking that is focused on deciding what to believe or what to do (Ennis, 1987). This type of thinking involves good reasoning, reasoned judgement and taking a rational approach (Bensley, 2011) and requires skilled and active interpretation and evaluation of observations, communications, information and argumentation (Fisher \& Scriven, 1997).

Critical thinking is a purposeful and goal-oriented metacognitive process directed at a predefined problem in which the solution requires multiple steps such as determining which data is relevant, evaluating the credibility of sources, making inferences, calculating likelihoods and making decisions (Paul, 1993; Wilkinson, 1996; Halpern, 2003; Dwyer, Hogan \& Stewart, 2011). Using a fundamental set of subskills (i.e. analysis, evaluation, and 
inference) effectively "increases the chances of producing a logical solution to a problem or a valid conclusion to an argument" (Dwyer, Hogan \& Stewart, 2011).

Critical thinkers have the skill to engage in ideation activities with reflective skepticism (McPeck, 1981), they question the statements, propositions and information (Mingers, 2000). It is an independent, open-minded way of thinking, with the ability to apply reasoning and logic to new or unfamiliar ideas, opinions and situations with no prejudgments. It is free from beliefs and irrational judgement.

b) Lateral thinking: Lateral thinking is an alternative type of creative thinking used in ideation processes. Individuals frequently follow their own past experiences or those of others to solve problems. In a complex environment, ideators face situations which do not lend themselves to the logical problem solving approach (Butler, 2010) and need unconventional thinking methods (Debone, 1970). The new and unconventional way of viewing and solving problems with a new angle is defined as lateral thinking. Lateral thinking has four key steps (Butler, 2010): (1) assumptions about the world should be tested continuously, (2) right questions should be asked, digging beneath the surface to understand the concept better, (3) a conscious and intentional effort must be made to be creative and (4) a well-reasoned, logical approach should accompany the thinking process, so that ideas proposed can stand up to analysis, reasoning and logic. Through application of these four phases continuously, lateral thinking presents an alternative to the hierarchical ordered process of vertical thinking in which a sequential process where every step has to be correct and justified before moving to subsequent stages (Waks, 1997). Restructuring the traditional thinking methods, lateral thinking paves the way for new idea creation and development (Waks, 1997).

c) Sensual/Visual thinking: Sometimes thinking process happens through sensory perceptions. Individuals use one of their senses to collect and evaluate information. Visual perception enables individuals to collect information from the environment in many ways. Shapes, colors, movements, dimension are "susceptible to definite and highly complex organization in space and time" (Arnheim, 1969, p. 18), providing rich information for the mind. Visual thinking is the "ability to visualize ideas: holistically, spatially, metaphorically and to be able to transform ideas through imaginative manipulation (McKim, 1980). It is sometimes referred to as picture thinking since the thinking process happens through visual processing in which information flows from visual sensors to cognitive processing organs (Das, Bennet \& Dutton, 2007). People who tend to collect information through visual thinking are excellent observers and use their visual ability in ideation processes by giving meaning to the information perceived and collected through their vision.

d) Design thinking: Design thinking is a cognitive methodology used by professional designers to find design solutions to problems. Multiple models of design thinking have emerged (Dorst, 2011) as many disciplines, including IT, business and entrepreneurship, borrowed the term 'design thinking' to apply its methodology for unique problem-solving. Based on a semantic foundation, Krippendorff (2006) defined design as a way of creating meaning rather than artefacts and indicated that meaning is the core of the design process and 


\section{Macrothink}

artefact is the result to communicate the created meaning to targeted audience (Krippendorff, 2006; Johansson-Sköldberg, Woodilla, \& Çetinkaya, 2013). Although the concept of design has been traditionally associated with the creation of tangible goods and products, now used in many disciplines, it refers to the design of symbolic and visual communications, activities and organized services, dealing with complex systems and uncertain environments (Glen, Suciu \& Baughn, 2014). Roger Martin (2004), pioneering the use of design thinking in business and entrepreneurship, defined it as the willingness and capability to build better solutions than existing ones.

Design thinking process has divergent and convergent phases, combining the former two thinking methods into a more complete methodology. It provides an approach for dealing with complex and ill-defined problems when there is a high level of uncertainty (Glen, et al., 2014). The focus of design thinking is to identify user needs in order to create appropriate solutions (Mueller \& Thoring, 2012). This kind of thinking is all-human-focused and it involves methods enabling empathy with people (Curedale, 2013). Designers are devoted to understanding the user experience and narrative. It is common for a design thinker to observe a customer's relation to a product for prolonged periods of time to understand the interaction between the user and the product and to gather data on improving this relation (Choi, 2014). It is an iterative process incorporating many components such as visualizing, experimenting, creating and validating of models and gathering feedback to continually improve the outcome (Glen, et al., 2014). The continuous loop of discovery, defining, developing and delivery is shown in Figure 1.

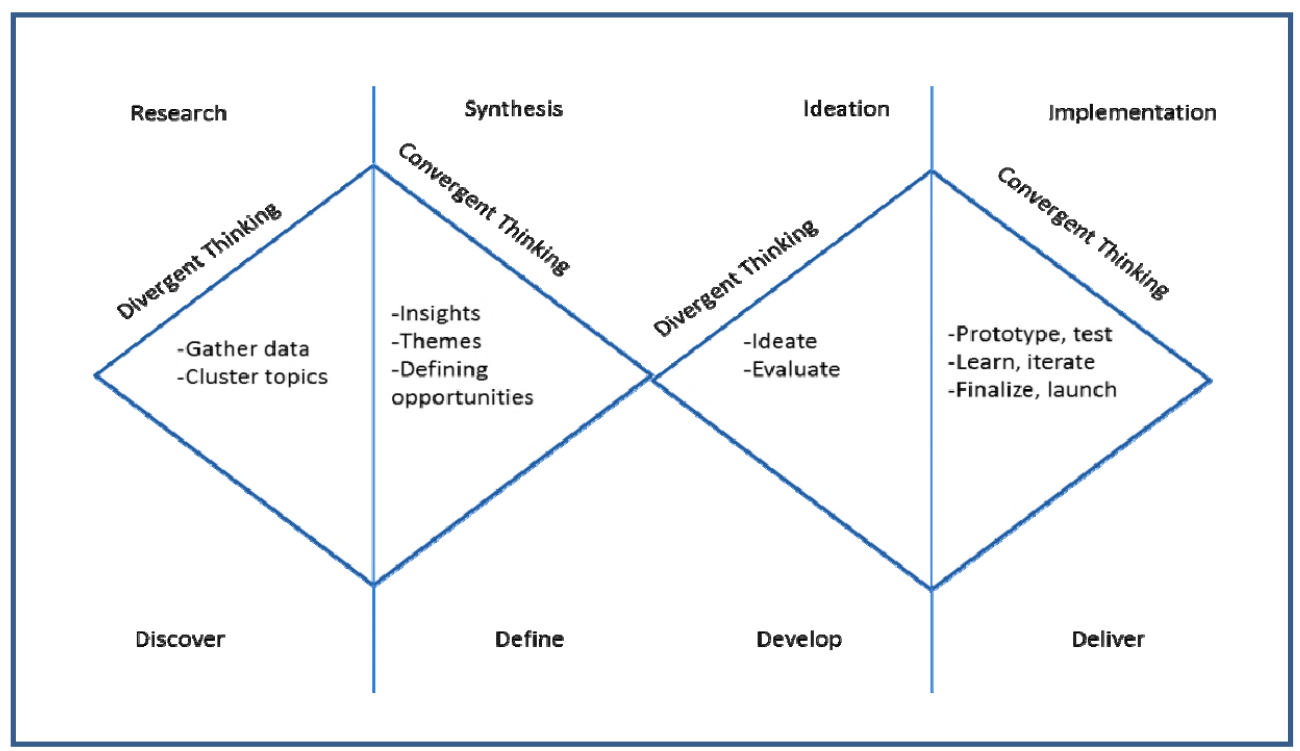

Figure 2. Adapted from design council (2006)

Brown and Wyatt (2010) indicate that design thinking does not only focus on innovating human centered products and services, but the ideation process itself is very much human. The approach enables the ideation team to use their ability to be intuitive, recognize the recurring patterns, construct ideas that has meaning as well as function and express 
themselves in many directions (Brown and Wyatt, 2010). Design thinking integrates and balances the analytical problem solving approaches with emotional, intuitive, inspirational and experience based problem solving through combining different thinking methods into one holistic approach.

\subsection{Using multiple Idea Development Methods Together}

A variety of idea development methods should be used together in stimulating and combining the aforementioned thinking methods. Practitioners created many team exercises and practices to drive the ideation process. Brainstorming, mind-mapping, remodeling and story-telling are among the best known methods.

Brainstorming is a commonly used method "for generating ideas, increasing creative efficacy, or finding solutions to problems" using divergent thinking and convergent thinking together (Wilson, 2013). It is a group ideation method applying a collaborative approach to innovation by leveraging different knowledge, experience and perspectives of team members, and building on ideas brought up by others (Curedale, 2013). Brainstorming can be used in many different occasions where new idea development is required such as new product, service, process development, finding solutions to specific and defined problems, supporting conceptual design by generating metaphors, finding new ways to do old things and improving the existing ideas (Wilson, 2013). The prerequisite for effective brainstorming is to provide a nonjudgmental, comfortable and safe environment where every person and every idea is of equal value (Curedale, 2013).

Mind-mapping is an idea generation method practiced through drawing diagrams "used to represent the affinities or connections between a number of ideas or things" (Curedale, 2013). Ideators start mind-mapping by putting an image, subject or key words in the center and continue by drawing branches with main themes radiating from the central image. Branches are defined with key images, symbols and key words associating with the central image (Mento, Martinelli \& Jones, 1999; Curedale, 2013). Branches represent nodes of concepts to further the ideation process. Sub-topics and concepts of lesser importance are represented with twigs (sub-nodes) connected to relevant branches. A fully developed mind-map is a hierarchy of linked nodes (Chik, Plimmer \& Hosking, 2007). Mind-mapping is a powerful tool to stimulate visual thinking. It provides a method of visual note-taking through the use of sketches, colors, images, codes, and symbols (Mento, et al., 1999). Mind-mapping method has many strengths. It allows the ideators to discover and identify the relationships and connections between different ideas and concepts. It helps categorize and organize different ideas and enables the team to make associations (Mento, et al., 1999).

New ideas and products are rarely in the breakthrough innovation category. Most of the new products in the market are a new version of the already existing ones. Two decades ago, Ernst\&Young \& ACNielsen (1999) studied 24,543 new products launched in the market and found that only $334(1.36 \%)$ of these products were breakthrough ideas. The rest of the new products were either line or category extensions or "me, too" products -products that are almost identical to the already existing ones in the market. Nielsen 2014 Breakthrough Innovation Report's results are no different. Out of 3,463 launches included in the study, only 
$14(0.40 \%)$ met the criteria to be considered a breakthrough idea (Hall, Wengel \& Eddie, 2014). These statistics show us that most of the entrepreneurs are launching either identical or very similar new products to the ones in the market. This brings up the need for effective remodeling. Remodeling is an idea generation method to find what is missing, not working or is unsatisfactory for the user and change the product/service for further improvement. Remodeling can be a category or line extension, finding a new market or use for a product or developing the product further. Learning and practicing remodeling tools and strategies will be helpful for the ideation team to increase the quality of their ideas.

Storytelling, storyboarding and scenario building are a group of similar methods used by ideators to understand the context and the use of a product (Gonçalves, Cardoso, \& Badke-Schaub, 2014). Team members develop a story of the future use of the product in a specific situation or in different contexts. Stories help the ideation team to understand the interaction between the product and the user in depth. The strength of these methods is in their flexibility and adaptability to the needs (Michalko, 2010; Curedale, 2013) of the group. These methods constitute a participative approach to ideation in which members "explore their own experiences and views of reality in a dramaturgical frame and construct new meaning” (Pässilä, Oikarinen, \& Kallio, 2013, p. 162). Story based methods help members understand how different people experience reality distinctly. Ideating by exploiting stories helps the team to understand the socially constructed structures and create collective meanings (Pässilä, et al., 2013, p. 162).

Game playing is frequently used to apply these methods in classes and idea generation sessions. Practitioners created hundreds of games and exercises such as "100 uses for an object" (remodeling exercise), persona development (story-telling exercise), image-ation (visual thinking exercise), thinking bubbles (mind-mapping exercise) and problem/challenge statements (brainstorming exercise) (Michalko, 2010; Gray, Brown \& Macanufo, 2010; Curedale, 2013). In many of these exercises, team members are required to use more than one thinking method and switch quickly from one to the other sharpening their ideation skills.

\subsection{Validating the Idea}

Validating the idea is the final phase of the systematic ideation approach. Validation enables the ideation team to understand the users' experience and reactions to the new idea. The idea is tested with one of the prototyping approaches and iterations are performed when necessary. There are many validation methods depending on the type of idea to be tested, level of commitment and fidelity. These methods vary from simple sketches to wireframes, mockups, pretotypes and prototypes.

Choice of method depends on the level of idea development and the purpose of validation. If the team aims to gain insight and inform their decision making for further stages of idea development, they may choose to have a quick, cheap low fidelity prototyping with very little or no investment (Curedale, 2013). Low fidelity prototypes have limited functionality and limited interaction, constructing the general look and feel of the idea to communicate, inform and educate the users. They may be used in earlier stages of idea development and help users visualize what the end product will look like (Rudd, Stern, \& Isensee, 1996). 
High fidelity prototypes are usually fully functional and interactive and are built to test the fully developed idea before launch. High fidelity prototypes are not as quick and cheap to build as low fidelity prototypes but they ensure accuracy and realistic use. They can be used for marketing and sales efforts even before the launch of the idea (Rudd, et al., 1996).

Low fidelity prototyping using drawings, sketches and pretotyping would be pertinent for educational purposes to show students how to test their ideas with a quick and inexpensive approach. In start-up reality, a fully functional prototype will help ventures test their idea before placing it in the market, seek funding and use their prototype as a means for marketing efforts. In both cases, prototyping is a tool to receive feedback about the idea and to continue improvement and iteration processes when necessary.

\section{Conclusion and Discussion}

Scholarly interest and recent research supports the view that entrepreneurship can be taught. Increasing numbers of educators and professionals prevail over the myth that entrepreneurs are born, not made (Kuratko, 2005). Entrepreneurship education should clearly be different in content and pedagogy than typical business education and should address experiential skill-building courses in negotiation, leadership, new product development, creative thinking and exposure to technological innovation (McMullen \& Long, 1987; Ronstadt, Vesper \& McMullen, 1988; Kuratko, 2005). Teaching and implementing ideation using creative thinking skills with an intentional, systematic and structured approach is one of the differentiators of entrepreneurship education.

A company's long term viability and competitiveness is dependent upon the effectiveness of its ideation processes at all levels of operations. Bjork (2012:17) suggest that "broadening of the scope and sources of innovation, together with an increased awareness of the importance of collaborative and social aspects of ideation have intriguing implications". Taking a proactive approach to ideation is crucial for entrepreneurs. Integrating ideation methodologies into each and every level of entrepreneurship education will make entrepreneurship students more successful and competitive in their future careers as entrepreneurs.

The methods we use to teach idea creation to our students need reevaluation and further scrutiny in consideration of enormous changes in the field of business and entrepreneurship. Five phased systematic approach presented in this paper ensures that individuals start ideation by observing their environment, gathering clues to recognize the opportunities and building diverse teams to assemble complementary skills and strengths. Ideation process continues with practicing a variety of thinking and idea generation methods together and finalizes with validating the idea.

An important limitation of this study is that it is restricted to the needs and specifics of entrepreneurship education. Further research will help customize the systematic ideation approach regarding various needs and demands of different industries. Consequently, such customization will carve the way to developing unique tools and methods to teach and implement ideation in many different fields entrepreneurs operate. Another limitation of the 
paper is that the methodology presented needs empirical testing. Future empirical studies will test systematic ideation approach to assess the student success in creating new and novel ideas using a proactive approach.

\section{References}

Amabile, T.M. (1996). Creativity in context: Update to "The Social Psychology of Creativity." Boulder, CO: Westview.

Amabile, T.M., Conti, R., Coon, H., Lazenby, J. \& Herron, M. (1996). Assessing the work environment for creativity. The Academy of Management Journal, 5(39), 1154-1184. http://doi.org/10.2307/256995

Arnheim, R. (1969). Visual thinking. Berkeley, CA: Univ of California Press.

Barron, F. (1955). The disposition toward originality. Journal of Abnormal and Social Psychology, 51, 478-485.

Barron, F., \& Harrington, D. M. (1981). Creativity, intelligence and personality. Annual Review of Psychology, 32, 439-476. http://doi.org/10.1146/annurev.ps.32.020181.002255

Basadur, M., Runco, M. A., \& Vega, L. A. (2000). Understanding how creative thinking skills, attitudes and behaviors work together: A causal process model. The Journal of Creative Behavior, 34(2), 77-100. https://doi.org/10.1002/j.2162-6057.2000.tb01203.x

Bensley, D. A. (2011). Rules for reasoning revisited: Toward a scientific conception of critical thinking. In C. P. Horvath \& J. M. Forte (Eds.), Critical thinking: Education in a competitive and globalizing world (pp. 1-45). NY: Nova Science Publishers, Inc.

Bergendahl, M., \& Magnusson, M. (2015). Creating Ideas for Innovation: Effects of Organizational Distance on Knowledge Creation Processes. Creativity and Innovation Management, 24(1), 87-101. https://doi.org/10.1111/caim.12097

Bjork, J. (2012). Knowledge domain spanner for ideation. Creativity and Innovation Management, 21(1), 17-27. https://doi.org/10.1111/j.1467-8691.2012.00627.x

Brown, T., \& Wyatt, J. (2010). Design thinking for social innovation. Development Outreach, 12(1), 29-43.

Butler, S. A. (2010). Solving business problems using a lateral thinking approach. Management Decision, 48(1), 58-64. https://doi.org/10.1108/00251741011014454

Chik, V., Plimmer, B., \& Hosking, J. (2007). Intelligent mind-mapping. In Proceedings of the 19th Australasian conference on computer-human interaction: entertaining user interfaces, 195-198.

Choi, D. Y. (2014). Bringing design capability into entrepreneurship: LMU and Otis. Annals of Entrepreneurship Education and Pedagogy, 390-394.

Cohen, W. M., \& Levinthal, D. A. (2000). Absorptive capacity: A new perspective on learning and innovation. Strategic Learning in a Knowledge economy, 39-67. 
https://dx.doi.org/10.2307/2393553

Colzato, L. S., Ozturk, A., \& Hommel, B. (2012). Meditate to create: the impact of focused-attention and open-monitoring training on convergent and divergent thinking. Frontiers in Psychology, 3, 116. https://doi.org/10.3389/fpsyg.2012.00116

Crossan, M. M., \& Apaydin, M. (2010). A multi-dimensional framework of organizational innovation: A systematic review of the literature. Journal of Management Studies, 47(6), 1154-1191. https://doi.org/10.1111/j.1467-6486.2009.00880.x

Curedale, R. (2013). 50 Brainstorming Methods: For Team and Individual Ideation. Topanga, CA: Design Community College Incorporated.

Dayan, M., Zacca, R., \& Di Benedetto, A. (2013). An exploratory study of entrepreneurial creativity: Its antecedents and mediators in the context of UAE firms. Creativity and Innovation Management, 22(3), 223-240. https://doi.org/10.1111/caim.12036

Das, M., Bennett, D. M., \& Dutton, G. N. (2007). Visual attention as an important visual function: an outline of manifestations, diagnosis and management of impaired visual attention. The British Journal of Ophthalmology, 91(11), 1556-1560. https://dx.doi.org/10.1136/bjo.2006.104844

Debone, E. E. (1970). Lateral Thinking. New York, NY: Penguin Books.

Dell'Era, C., \& Verganti, R. (2010). Collaborative strategies in design-intensive industries: knowledge diversity and innovation. Long Range Planning, 43(1), 123-141.https://dx.doi.org/10.1016/j.lrp.2009.10.006

Design Council (2006). Double diamond design process. Retrieved from https://www.designcouncil.org.uk/news-opinion/design-process-what-double-diamond

Dobson, J.A., Jacobs, E., \& Dobson, A. (2017). Toward an experiential approach to entrepreneurship education. Journal of Higher Education Theory and Practice, 17(3), 57-69.

Dorst, K. (2011). The core of 'design thinking' and its application. Design studies, 32(6), 521-532. https://dx.doi.org/10.1016/j.destud.2011.07.006

Dwyer, C. P., Hogan, M. J., \& Stewart, I. (2011). The promotion of critical thinking skills through argument mapping. In C. P. Horvath \& J. M. Forte (Eds.), Critical thinking: Education in a competitive and globalizing world, 97-122. NY: Nova Science Publishers, Inc.

Ennis, R. (1987). A taxonomy of critical thinking abilities and dispositions. In J. Baron \& R. Sternberg (Eds.), Teaching thinking skills: Theory and practice, 9-26. New York: W.H. Freeman.

Ernst \& Young and ACNielsen. (1999). New Product introduction - Successful Innovation/Failure: A Fragile Boundary. ECR Europe publications.

Farid, F., El-Sharkawy, A. R., \& Austin, L. K. (1993). Managing for creativity and innovation in A/E/C organizations. Journal of Management in Engineering, 9(4), 399-409. 
https://dx.doi.org/10.1061/(ASCE)9742-597X(1993)9:4(399)

Fayolle, A., Gailly, B., \& Lassas-Clerc, N. (2006). Assessing the impact of entrepreneurship education programmes: a new methodology. Journal of European Industrial Training, 30(9), 701-720. https://dx.doi.org/10.1108/03090590610715022

Finke, R. A., Ward, T. B., \& Smith, S. M. (1992). Creative cognition: Theory, research and applications. Cambridge, MA: MIT Press.

Fisher, A., \& Scriven, M. (1997). Critical thinking: Its definition and assessment. Point Reyes, CA: Edge Press.

Glen, R., Suciu, C., \& Baughn, C. (2014). The need for design thinking in business schools. Academy of Management Learning \& Education, 13(4), 653-667. https://dx.doi.org/10.5465/amle.2012.0308

Guilford, J. P. (1950). Creativity. American Psychologist, 5, 444-454.

Gonçalves, M., Cardoso, C., \& Badke-Schaub, P. (2014). What inspires designers? Preferences on inspirational approaches during idea generation. Design studies, 35(1), 29-53. https://dx.doi.org/10.1016/j.destud.2013.09.001

Gray, D., Brown, S., \& Macanufo, J. (2010). Gamestorming: A playbook for innovators, rulebreakers, and changemakers. CA, USA: O'Reilly Media, Inc.

Guo, J., Su, Q., \& Zhang, Q. (2017). Individual creativity during the ideation phase of product innovation: An interactional perspective. Creativity and Innovation Management, 26(1), 31-48. https://dx.doi.org/10.1111/caim.12205

Hall, T., Wengel, R., \& Eddie, Y. (2014). Nielsen breakthrough innovation report. New York, NY: The Nielsen Company Publications.

Halpern, D.F. (2003). Thought \& Knowledge: An Introduction to Critical Thinking (4th ed.) New Jersey, USA: Laurence Erlbaum Associates.

Janszen, F. (2000). The Age Innovation: Making Business a Competence Creativity not a Coincidence. London, UK: Pearsion Education Limited.

Johansson, F. (2004). The Medici effect. Boston, MA: Harvard Business School Press.

Johansson-Sköldberg, U., Woodilla, J., \& Çetinkaya, M. (2013). Design thinking: past, present and possible futures. Creativity and innovation management, 22(2), 121-146. https://dx.doi.org/10.1111/caim.12023

Jolley, N. (1998). The light of the soul: Theories of ideas in Leibniz, Malebranche and Descartes. NY: Clarendon Press.

Koen, P., Ajamian, G., Burkart, R., Clamen, A., Davidson, J., D'Amore, R., Elkins, C., Herald, K., Incorvia, M., Johnson, A., Karol, R., Seibert, R., Slavejkov, A. \& Wagner, K. (2001). Providing clarity and a common language to the "fuzzy front end". Research-Technology Management, 44(2), 46-55. 
Krippendorff, K. (2006). The semantic turn: A new foundation for design. Boca Raton, FL: Taylor \& Francis.

Kuratko, D. F. (2005). The emergence of entrepreneurship education: Development, trends, and challenges. Entrepreneurship theory and practice, 29(5), 577-598. https://dx.doi.org/10.1111/j.1540-6520.2005.00099.x

Leonard, D., \& Sensiper, S. (1998). The role of tacit knowledge in group innovation. California Management Review, 40(3), 112-132. https://dx.doi.org/10.2307/41165946

Link, A. N. (2017). Ideation, entrepreneurship and innovation. Small Business Economics, 48, 279-285. https://dx.doi.org/10.1007/s11187-016-9782-1

MacKinnon, D. W. (1965). Personality and the realization of creative potential. American Psychologist, 20, 273-281. https://dx.doi.org/10.1037/h0022403

Machlup, F. (1980). Knowledge: its creation, distribution, and economic significance. Volume 1, Knowledge and knowledge production. Princeton, NJ: Princeton University Press.

Mahon, N. (2017). Basics Advertising 03: Ideation. London, UK: Bloomsbury Publishing.

Martin, R. (2004). The design of business. Rotman Management, 5(1), 6-10.

Mascia, D., Magnusson, M. \&Bjork, J. (2015). The role of social networks in organizing ideation, creativity and innovation: An introduction. Creativity and Innovation Management, 24(1): 102-108. https://dx.doi.org/10.1111/caim.12111

McCall, G. J. (1984). Systematic field observation. Annual Review of Sociology, 10(1), 263-282. https://dx.doi.org/10.1146/annurev.so.10.080184.001403

McKim, R. H. (1980). Thinking visually: A strategy manual for problem solving. Belmont, CA: Lifetime Learning Publications.

McMullan, W. E., \& Long, W. A. (1987). Entrepreneurship education in the nineties. Journal of Business Venturing, 2(3), 261-275. https://dx.doi.org/10.1016/0883-9026(87)90013-9

McPeck, J. (1981). Critical thinking and education. New York, NY: St. Martin's Press.

Mednick, S. (1962). The associative basis of the creative process. Psychological Review, 69(3), 220. https://dx.doi.org/10.1037/h0048850

Mento, A. J., Martinelli, P., \& Jones, R. M. (1999). Mind mapping in executive education: applications and outcomes. Journal of Management Development, 18(4), 390-416. https://dx.doi.org/10.1108/02621719910265577

Michalko, M. (2010). Thinkertoys: A handbook of creative-thinking techniques. New York, NY: Ten Speed Press.

Mingers, J. (2000). What is it to be critical? Management Learning, 31(2), 219-237. https://dx.doi.org/10.1177/1350507600312005

Miyasaki, N. (2014). Can universities really help students start ventures? Annals of 
https://dx.doi.org/10.4337/9781783471454.00016

Morris, M. H., Webb, J. W., Fu, J., \& Singhal, S. (2013). A competency-based perspective on entrepreneurship education: conceptual and empirical insights. Journal of Small Business Management, 51(3), 352-369. https://dx.doi.org/10.1111/jsbm.12023

Mueller, R., \& Thoring, K. (2012). Design Thinking vs. Lean Startup: A comparison of two usr-driven innovation strategies. Proceedings from Leading Innovation Through Design: 2012 International Design Management Research Conference, Boston, MA. USA.

Nieto, M. J., \& Santamaría, L. (2007). The importance of diverse collaborative networks for the novelty of product innovation. Technovation, 27(6-7), 367-377. https://dx.doi.org/10.1016/j.technovation.2006.10.001

Osborn, A.F. (1953). Applied Imagination, Principles and Procedures of Creative Thinking. New York: Charles Scribner's Sons.

Papo, D. (2007). Where do Ideas Come From? Brain Activity and Economic Systems. European Journal of Economic and Social Systems, 20:2, 163-186.

Pässilä, A., Oikarinen, T., \& Kallio, A. (2013). Creating dialogue by storytelling. Journal of Workplace Learning, 25(3), 159-177. https://dx.doi.org/10.1108/13665621311306547

Paul, R.W. (1993). Critical Thinking - what every person needs to survive in a rapidly changing world (3rd ed.). Santa Rosa, CA: Foundation for Critical Thinking.

Parayil, G. (1991). Schumpeter on Invention, Innovation and Technological Change. Journal of the History of Economic Thought, 13(1), 78-89.

Robertson, S. I. (2013). Types of thinking. NY: Routledge.

Ronstadt, R., Vesper, K. H., \& McMullan, W. E. (1988). Entrepreneurship: Today courses, tomorrow degrees? Entrepreneurship theory and practice, 13(1), 7-13. https://doi.org/10.1177/104225878801300102

Rudd, J., Stern, K., \& Isensee, S. (1996). Low vs. high-fidelity prototyping debate. Interactions, 3(1), 76-85. https://dx.doi.org/10.1145/223500.223514

Runco, M. A. (1991). Divergent thinking. Norwood, NJ: Ablex.

Stouffer W.B, Russell J.S. \& Oliva, M.G. (2004). Making the Strange Familiar: Creativity and the future of engineering education. Proceedings from 2004 American Society for Engineering Education Annual Conference \& Exposition, Salt Lake City, UTAH American Society for Engineering Education.

Torrance, E. P. (1963). Creativity. Washington, D.C.: National Education Association.

Valacich, J. S., Jung, J. H., \& Looney, C. A. (2006). The effects of individual cognitive ability and idea stimulation on idea-generation performance. Group Dynamics: Theory, Research, and Practice, 10(1), 1-15. https://dx.doi.org/10.1037/1089-2699.10.1.1 


\section{Macrothink}

Journal of Entrepreneurship and Business Innovation

ISSN 2332-8851 2018, Vol. 5, No. 2

Waks, S. (1997). Lateral thinking and technology education. Journal of Science Education and Technology, 6(4), 245-255. https://dx.doi.org/10.1023/A:1022534310151

Wallas, G. (1926). The art of thought. London, UK: Jonathan Cape.

Weick, K. E. (1968). Systematic observational methods. The Handbook of Social Psychology, $2,357-451$.

Wilkinson J.M., (1996). Nursing process: A critical thinking approach $\left(2^{\text {nd }}\right.$ Ed.). Menlo Park, CA: Addison Wesley Nursing.

Wilson, C. (2013). Brainstorming and beyond: a user-centered design method. Chicago: Morgan Kaufmann Publishers.

Woodman, R.W., Sawyer, J.E. \& Griffin, R.W. (1993). Toward a theory of organizational creativity. Academy of Management Review, 18, 293-321. https://dx.doi.org/10.5465/AMR.1993.3997517

\section{Copyright Disclaimer}

Copyright for this article is retained by the author (s), with first publication rights granted to the journal.

This is an open-access article distributed under the terms and conditions of the Creative Commons Attribution license (http://creativecommons.org/licenses/by/3.0/). 